\title{
Results from the CERN pilot CLOUD experiment
}

\author{
J. Duplissy ${ }^{1}$, M. B. Enghoff ${ }^{2}$, K. L. Aplin ${ }^{3}$, F. Arnold ${ }^{4}$, H. Aufmhoff ${ }^{4}$, M. Avngaard ${ }^{2}$, U. Baltensperger ${ }^{5}$, T. Bondo ${ }^{2}$,

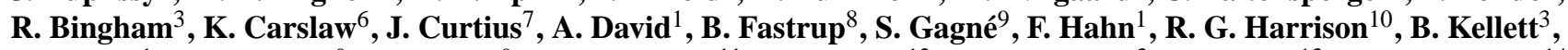 \\ J. Kirkby ${ }^{1}$, M. Kulmala ${ }^{9}$, L. Laakso ${ }^{9}$, A. Laaksonen ${ }^{11}$, E. Lillestol ${ }^{12}$, M. Lockwood ${ }^{3}$, J. Mäkelä ${ }^{13}$, V. Makhmutov ${ }^{14}$, \\ N. D. Marsh ${ }^{2}$, T. Nieminen ${ }^{9}$, A. Onnela ${ }^{1}$, E. Pedersen ${ }^{8}$, J. O. P. Pedersen ${ }^{2}$, J. Polny ${ }^{2}$, U. Reichl ${ }^{4}$, J. H. Seinfeld ${ }^{15}$, \\ M. Sipilä ${ }^{9}$, Y. Stozhkov ${ }^{14}$, F. Stratmann ${ }^{16}$, H. Svensmark ${ }^{2}$, J. Svensmark ${ }^{2}$, R. Veenhof ${ }^{1}$, B. Verheggen ${ }^{5}$, Y. Viisanen ${ }^{17}$, \\ P. E. Wagner ${ }^{18}$, G. Wehrle ${ }^{5}$, E. Weingartner ${ }^{5}$, H. Wex ${ }^{16}$, M. Wilhelmsson ${ }^{1}$, and P. M. Winkler ${ }^{18}$ \\ ${ }^{1}$ CERN, PH Department, Geneva, Switzerland \\ ${ }^{2}$ DTU Space, National Space Institute, Center for Sun-Climate Research, Copenhagen, Denmark \\ ${ }^{3}$ Rutherford Appleton Laboratory, Space Science \& Technology Department, Chilton, UK \\ ${ }^{4}$ Max-Planck Institute for Nuclear Physics, Heidelberg, Germany \\ ${ }^{5}$ Paul Scherrer Institut, Laboratory of Atmospheric Chemistry, Villigen, Switzerland \\ ${ }^{6}$ University of Leeds, School of Earth and Environment, Leeds, UK \\ ${ }^{7}$ Goethe-University of Frankfurt, Institute for Atmospheric and Environmental Sciences, Frankfurt am Main, Germany \\ ${ }^{8}$ University of Aarhus, Institute of Physics and Astronomy, Aarhus, Denmark \\ ${ }^{9}$ Helsinki Institute of Physics and University of Helsinki, Department of Physics, Helsinki, Finland \\ ${ }^{10}$ University of Reading, Department of Meteorology, Reading, UK \\ ${ }^{11}$ University of Kuopio, Department of Physics, Kuopio, Finland \\ ${ }^{12}$ University of Bergen, Institute of Physics, Bergen, Norway \\ ${ }^{13}$ Tampere University of Technology, Department of Physics, Tampere, Finland \\ ${ }^{14}$ Lebedev Physical Institute, Solar and Cosmic Ray Research Laboratory, Moscow, Russia \\ ${ }^{15}$ California Institute of Technology, Division of Chemistry and Chemical Engineering, Pasadena, USA \\ ${ }^{16}$ Leibniz Institute for Tropospheric Research, Leipzig, Germany \\ ${ }^{17}$ Finnish Meteorological Institute, Helsinki, Finland \\ ${ }^{18}$ University of Vienna, Institute for Experimental Physics, Vienna, Austria
}

Received: 7 August 2009 - Published in Atmos. Chem. Phys. Discuss.: 2 September 2009

Revised: 18 December 2009 - Accepted: 15 January 2010 - Published: 15 February 2010

\begin{abstract}
During a 4-week run in October-November 2006, a pilot experiment was performed at the CERN Proton Synchrotron in preparation for the Cosmics Leaving OUtdoor Droplets (CLOUD) experiment, whose aim is to study the possible influence of cosmic rays on clouds. The purpose of the pilot experiment was firstly to carry out exploratory measurements of the effect of ionising particle radiation on aerosol formation from trace $\mathrm{H}_{2} \mathrm{SO}_{4}$ vapour and secondly to provide technical input for the CLOUD design. A total of 44 nucleation bursts were produced and recorded, with formation rates of particles above the $3 \mathrm{~nm}$ detection threshold of between 0.1 and $100 \mathrm{~cm}^{-3} \mathrm{~s}^{-1}$, and growth rates between 2 and $37 \mathrm{~nm} \mathrm{~h}^{-1}$. The corresponding $\mathrm{H}_{2} \mathrm{SO}_{4}$ con-
\end{abstract}

Correspondence to: J. Duplissy

(jonathan.duplissy@ cern.ch) centrations were typically around $10^{6} \mathrm{~cm}^{-3}$ or less. The experimentally-measured formation rates and $\mathrm{H}_{2} \mathrm{SO}_{4}$ concentrations are comparable to those found in the atmosphere, supporting the idea that sulphuric acid is involved in the nucleation of atmospheric aerosols. However, sulphuric acid alone is not able to explain the observed rapid growth rates, which suggests the presence of additional trace vapours in the aerosol chamber, whose identity is unknown. By analysing the charged fraction, a few of the aerosol bursts appear to have a contribution from ion-induced nucleation and ion-ion recombination to form neutral clusters. Some indications were also found for the accelerator beam timing and intensity to influence the aerosol particle formation rate at the highest experimental $\mathrm{SO}_{2}$ concentrations of $6 \mathrm{ppb}$, although none was found at lower concentrations. Overall, the exploratory measurements provide suggestive evidence for ion-induced nucleation or ion-ion recombination as sources of aerosol

Published by Copernicus Publications on behalf of the European Geosciences Union. 
particles. However in order to quantify the conditions under which ion processes become significant, improvements are needed in controlling the experimental variables and in the reproducibility of the experiments. Finally, concerning technical aspects, the most important lessons for the CLOUD design include the stringent requirement of internal cleanliness of the aerosol chamber, as well as maintenance of extremely stable temperatures (variations below $0.1^{\circ} \mathrm{C}$ ).

\section{Introduction}

In its Fourth Assessment Report, 2007, the Intergovernmental Panel on Climate Change (IPCC) attributes more than $90 \%$ of the observed climate warming since 1900 to the rise of anthropogenic greenhouse gases in the atmosphere (IPCC, 2007). Aerosols and clouds are recognised as representing the largest uncertainty in the current understanding of climate change. The IPCC estimates that changes of solar irradiance (direct solar forcing) have made only a small (7\%) contribution to the observed warming. However, large uncertainties remain on other solar-related contributions, such as the effects of changes of ultra-violet (UV) radiation or galactic cosmic rays on aerosols and clouds (Svensmark and Friis-Christensen, 1997; Carslaw, Harrison and Kirkby, 2002; Lockwood and Fröhlich, 2007; Kirkby, 2007; Enghoff and Svensmark, 2008; Kazil, Harrison and Lovejoy, 2008; Siingh, 2008).

Concerning the effects of cosmic rays on aerosols, early studies (Bricard et al., 1968; Vohra et al., 1984) have demonstrated ultrafine particle production from ions in the laboratory, at ion production rates typically found in the lower atmosphere; this has also been found in more recent laboratory experiments under conditions closer to those found in the atmosphere (Svensmark et al., 2007; Enghoff et al., 2008). Observations of ion-induced nucleation in the atmosphere have also been reported (Eickhorn et al., 2002; Lee et al., 2003). Laboratory measurements have further quantified the effect of charge on particle formation (Winkler et al., 2008) and have shown that ions are indeed capable, under certain conditions, of suppressing or even removing the barrier to nucleation in embryonic molecular clusters of water and sulphuric acid at typical atmospheric concentrations (Lovejoy, Curtius and Froyd, 2004).

The present results, while suggestive, are insufficient to unambiguously establish an effect of galactic cosmic rays on cloud condensation nuclei, clouds and climate, or to reach reliable quantitative estimates of such effects (Kazil et al., 2006; Yu et al., 2008; Pierce and Adams, 2009). The uncertainties largely stem from poorly-known aerosol nucleation and growth rates into cloud condensation nuclei (CCN). Experiments are planned for the CLOUD facility at CERN to resolve this deficiency (CLOUD Collaboration, 2000).
The concept of CLOUD is to recreate atmospheric conditions inside a large chamber in which aerosols, cloud droplets and ice particles can be formed, and to expose the chamber to a particle beam at CERN, which closely replicates natural cosmic rays. The chamber is equipped with a wide range of instrumentation to monitor and analyse its contents. In contrast with experiments in the atmosphere, CLOUD can compare processes when the cosmic ray beam is present and when it is not. In this way cosmic ray-aerosol-cloud microphysics can be studied under carefully controlled laboratory conditions.

A pilot CLOUD experiment was performed at the CERN Proton Synchrotron (PS) during a 4-week run in OctoberNovember 2006. The aims were a) to begin exploratory studies of the effect of ionising particle radiation on aerosol formation from trace sulphuric acid vapour at typical atmospheric concentrations, and $b$ ) to provide technical input for the CLOUD design. This paper presents the results from the 2006 run. The paper is organised as follows: the experimental apparatus is presented in $\S 2$, the experimental results in $\S 3$, and the main technical lessons for the CLOUD design in $\S 4$.

\section{Apparatus}

\subsection{Aerosol chamber, UV system and field cage}

A schematic diagram of the pilot CLOUD experiment is shown in Fig. 1. The experimental setup is based on the SKY design (Svensmark et al., 2007) and the CLOUD proposal (CLOUD Collaboration, 2000). The aerosol chamber dimensions were $2 \times 2 \times 2 \mathrm{~m}^{3}$. It was constructed from passivated AISI 304 stainless steel sheets in a modular design to allow easy assembly, disassembly and transport. The sides of the chamber were sealed against a box frame with silicone $\mathrm{O}$ rings.

One wall of the chamber was replaced with a polytetrafluoroethylene (PTFE) window to allow the contents to be illuminated by UV light of $254 \mathrm{~nm}$ wavelength from a bank of seven fluorescent tubes (Philips TUV64T5 low pressure mercury vapour lamps, each $150 \mathrm{~cm}$ length and $75 \mathrm{~W}$ power). An aluminium honeycomb collimator (of $80 \mathrm{~mm}$ depth and $6.35 \mathrm{~mm}$ cell size, and painted matt black) was located between the UV lamps and the PTFE window to improve the uniformity of illumination within the chamber. With the honeycomb in place, the maximum UV intensity was $3 \mathrm{~mW} / \mathrm{m}^{2}$, integrated over the narrow emission line at $254 \mathrm{~nm}$. The honeycomb collimator was removed for a few special tests at higher maximum intensity $\left(80 \mathrm{~mW} / \mathrm{m}^{2}\right.$, measured at the far side of the chamber) but with poorer uniformity. The purpose of the UV light is to photo-dissociate ozone in the chamber to generate reactive oxygen and hence - in the presence of water vapour - also hydroxyl radicals. In turn the hydroxyl 
radicals oxidise sulphur dioxide in the chamber to form sulphuric acid.

A field cage provided electric fields of up to $20 \mathrm{kV} / \mathrm{m}$ in the chamber. When activated, the electric field swept small ions from the chamber in about one second. The field cage comprised two $1.8 \times 1.8 \mathrm{~m}^{2}$ stainless steel electrodes at voltages of up $+20 \mathrm{kV}$ and $-20 \mathrm{kV}$, respectively. The electrodes were separated by $1.8 \mathrm{~m}$ distance and supported at their corners by polyoxymethylene (Delrin) high voltage standoffs. One of the long hollow Delrin supports between the two electrodes contained a resistor divider chain (totalling $9.6 \mathrm{G} \Omega$ ) to define the voltages on 23 field wires that were evenly spaced between the two electrodes and arranged along a $1.8 \times 1.8 \mathrm{~m}^{2}$ perimeter.

\subsection{Gas system}

In order to suppress contaminants (trace condensable vapours, radon and background aerosols) in the air supply for the chamber, ultrapure air was obtained from the evaporation of cryogenic liquid $\mathrm{N}_{2}(99.995 \%)$ and liquid $\mathrm{O}_{2}(99.998 \%)$ (Carbagas), which were mixed in the gas volume ratio 79\% and $21 \%$, respectively. Water vapour from a Goretex tube humidifier, and trace amounts of $\mathrm{O}_{3}$ and $\mathrm{SO}_{2}$, were added to the inlet air. The $\mathrm{O}_{3}$ was generated by exposing a small fraction of the ultrapure air supply in a fused quartz tube to UV irradiation below $240 \mathrm{~nm}$. The $\mathrm{SO}_{2}$ was provided from a pressurised nitrogen gas cylinder containing $500 \mathrm{ppm} \mathrm{SO}_{2}$ (99.9\%) (Carbagas); it was diluted with ultrapure air to $5 \mathrm{ppm}$ before entering the aerosol chamber where it was further diluted to a few ppb. During the early runs, de-ionised water was used in the humidifier. However this was later replaced by Milli-Q ultrapure water (Millipore Corporation) to suppress organic contaminants. With all sampling instruments (\$2.3) operating, the inlet air flow rate was $50 \mathrm{l} / \mathrm{min}$ to maintain a constant chamber pressure of 1.3 mbar above the ambient atmospheric pressure ( 965 mbar mean absolute value).

\subsection{Analysing instruments}

The contents of the chamber were analysed by several instruments attached to sampling probes arranged along the mid-plane of the chamber, corresponding to zero potential between the $\mathrm{HV}$ electrodes.

Aerosol particles were measured with a battery of five condensation particle counters (two TSI 3025 and three TSI 3010 CPCs) set to different thresholds. The $50 \%$ cutoff values were at about 3, 3, 5, 5.6 and $7.2 \mathrm{~nm}$, respectively. However the cutoffs were not sharp (the $70 \%$ detection efficiencies occurred at about 1-2.5 nm larger sizes). The detection efficiencies were calibrated in the laboratory using sulphuric acid aerosol particles generated with a nebuliser and then size-selected by a nano differential mobility analyser (DMA) (Hermann et al., 2005). In addition to the fast particle size measurement provided by the CPC battery, a finer-

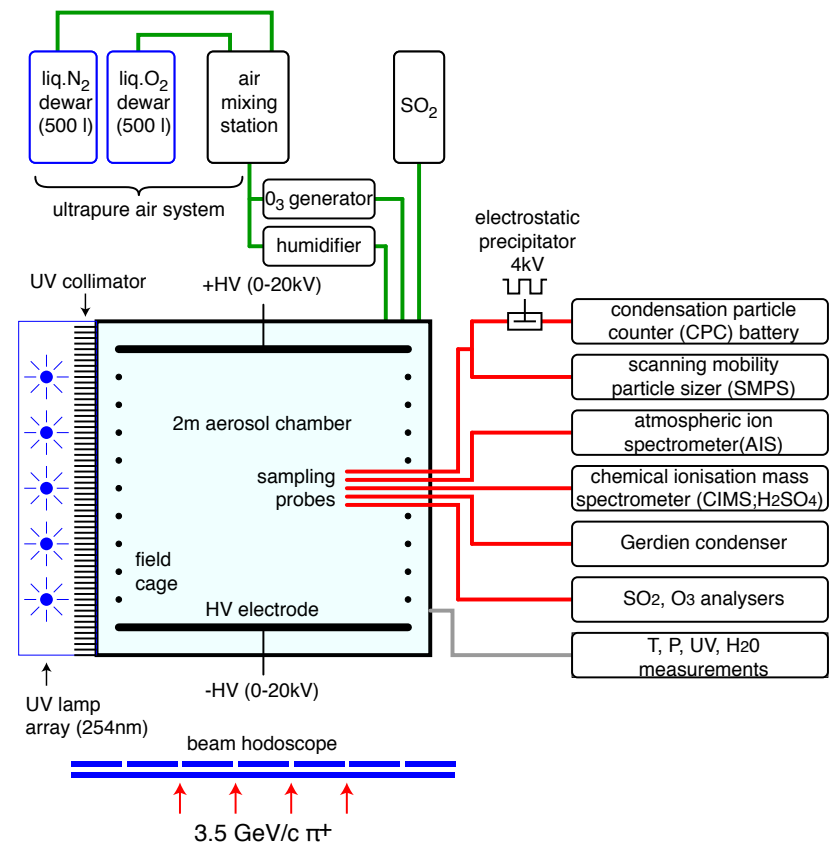

Fig. 1. Schematic diagram of the 2006 pilot CLOUD experiment.

grained, but slower, particle size distribution was provided by a scanning mobility particle sizer (SMPS). However, due to space constraints, a long sampling line had to be installed for the SMPS and so transmission losses imposed an effective threshold of about $20 \mathrm{~nm}$. For this reason, the SMPS measurements have not been used for the results reported here.

Ions and charged aerosols were measured with a Gerdien counter (Gerdien, 1905; Aplin and Harrison, 2000), air ion spectrometer (AIS) and electrostatic precipitator placed in the inlet line of the CPC battery. The precipitator was switched between two levels $(0$ and $4 \mathrm{kV})$ every $40 \mathrm{~s}$ to measure the total and uncharged aerosol concentrations, respectively. The AIS (Mirme et al., 2007; Asmi et al., 2009) measured the size distributions of positively charged and negatively charged particles simultaneously. The mobility range covered by the instrument is between 2.39 and $0.001 \mathrm{~cm}^{2} \mathrm{~V}^{-1} \mathrm{~s}^{-1}$ which correspond to mobility diameters between 0.8 and $40 \mathrm{~nm}$. Each polarity has its own Differential Mobility Analyzer (DMA) divided into 21 different isolated electrometers, allowing all 21 size channels to be measured simultaneously. The measurement cycle for obtaining one positive and one negative size distribution was just over two minutes.

For part of the run, gas-phase sulphuric acid was measured with a chemical ionisation mass spectrometer (CIMS) (Möhler and Arnold, 1992; Reiner et al., 1994; Curtius et al., 1998). The CIMS consists of an ion flow reactor coupled to a quadrupole ion trap mass spectrometer. The detection limit for $\mathrm{H}_{2} \mathrm{SO}_{4}$ is about $0.02 \mathrm{pptv}\left(5 \times 10^{5} \mathrm{~cm}^{-3}\right)$, for one minute time resolution. Commercial instruments were used 
to measure the concentrations of $\mathrm{O}_{3}$ (Teledyne 400A) and $\mathrm{SO}_{2}$ (Thermo $43 \mathrm{CTL}$ ). The chamber was instrumented to measure temperature (3 sensors), relative humidity (3) and pressure (1). The UV intensity was calibrated during special runs, using three different UV sensors.

\subsection{CERN particle beam}

The apparatus was installed on the T11 beamline in the East Hall at the CERN PS. During selected periods, the chamber was exposed to a $3.5 \mathrm{GeV} / \mathrm{c}$ positively-charged pion $\left(\pi^{+}\right)$ beam from a secondary target. Pions of this energy correspond closely to the characteristic energies and ionisation densities of cosmic ray muons penetrating the lower troposphere. The beam intensity, horizontal profile and vertical profile were measured by a plastic scintillation counter hodoscope of overall size $140 \times 140 \mathrm{~cm}^{2}$, comprising 7 vertical counters of $140 \times 20 \mathrm{~cm}^{2}$ followed by 7 horizontal counters of the same dimensions. The beam optics were adjusted to provide a wide transverse profile; the beam size in the chamber was about $1 \mathrm{~m}$ horizontally by $1.2 \mathrm{~m}$ vertically.

The beam intensity could be adjusted to provide equilibrium ion-pair (i.p.) concentrations in the chamber of up to about 10000 i.p. $\mathrm{cm}^{-3}(\$ 3.1)$, which is about a factor 10 higher than typical atmospheric concentrations in the lower troposphere. Any intermediate setting between this maximum and the cosmic ray background level could be reached by adjusting the beam collimators. With no beam and the clearing field on, the ion-pair concentration could be further reduced, reaching about 1 i.p. $\mathrm{cm}^{-3}$ at $20 \mathrm{kV} / \mathrm{m}$.

\section{Results}

\subsection{Ion-pair concentration vs. beam intensity}

We will provide here a simple estimate of the expected ionpair concentration in the chamber as a function of beam intensity, in order to make a comparison with the experimental measurements. Assuming low aerosol concentrations in the chamber, the dominant ion loss mechanism is ion-ion recombination. Under these conditions, the evolution of the concentration of positive or negative ions, $n_{ \pm}\left[\mathrm{cm}^{-3}\right]$ is given by (Tammet et al., 2006)

$\frac{d n_{ \pm}}{d t}=Q-\alpha n_{ \pm}^{2}$

where $Q\left[\mathrm{~cm}^{-3} \mathrm{~s}^{-1}\right]$ is the ion-pair production rate and $\alpha$ $\left[1.6 \times 10^{-6} \mathrm{~cm}^{3} \mathrm{~s}^{-1}\right]$ is the ion-ion recombination coefficient (Tammet and Kulmala, 2005). At equilibrium, $d n_{ \pm} / d t=0$ and Eq. 1 becomes

$n_{ \pm}=\sqrt{Q / \alpha}$

Galactic cosmic rays traversing the chamber produce a mean ionisation rate, $Q_{c}\left[\mathrm{~cm}^{-3} \mathrm{~s}^{-1}\right]$. Natural radioactivity, such as ${ }^{222} \mathrm{Rn}$ decay, can produce comparable or even several times higher ionisation rates at ground level than those from galactic cosmic rays. However the contribution of natural radioactivity in the chamber is negligible since the air is derived from cryogenic liquids. The mean ionisation rate from galactic cosmic rays at ground level is about 2 i.p. $\mathrm{cm}^{-3} \mathrm{~s}^{-1}$ (Tammet et al., 2006; Usoskin and Kovaltsov, 2006). Using this value in Eq. 2 results in an expected equilibrium ion-pair concentration at zero beam intensity, $n_{ \pm}=\sqrt{2 / 1.6 \times 10^{-6}}=1100 \mathrm{~cm}^{-3}$, in the absence of any losses other than ion-ion recombination. The ion-pair lifetime due to ion-ion recombination is $\tau=1 / \sqrt{\alpha Q}=560 \mathrm{~s}$. Additional ion sinks such as pre-existing aerosols and the walls of the chamber will reduce the equilibrium ion concentration below $1100 \mathrm{~cm}^{-3}$.

When the chamber is exposed to the accelerator beam, there is an additional ionisation rate, $Q_{b}\left[\mathrm{~cm}^{-3} \mathrm{~s}^{-1}\right]$, that is directly proportional to the time-averaged beam rate, $N_{b}$ $\left[\mathrm{s}^{-1}\right]$. Making the simple assumption that the ion pairs created within the limited $(\sim 1 \mathrm{~m})$ aperture of the beam are uniformly diluted over the entire chamber volume by diffusion and air flow,

$Q_{b}=N_{b} I l / V$

where $I=61$ i.p. $\mathrm{cm}^{-1}$ is the mean ionisation per $\mathrm{cm}$ for a $3.5 \mathrm{GeV} / \mathrm{c} \pi^{+}$in air at s.t.p. (Smirnov, 2005), $l=200 \mathrm{~cm}$ is the path length of a beam particle in the chamber, and $V=8 \times 10^{6} \mathrm{~cm}^{3}$ is the chamber volume. Equation (3) therefore provides the following relationship between mean ionpair production rate in the chamber and beam intensity

$Q_{b}=1.5 \times 10^{-3} N_{b}$

The maximum beam rate in the CERN T11 beamline is $N_{b}^{\max } \sim 220 \mathrm{kHz}$, which indicates a maximum ionisation rate, $Q_{b}^{\max }=330 \mathrm{~cm}^{-3} \mathrm{~s}^{-1}$. This is about a factor 160 higher than the ionisation rate from galactic cosmic rays. From Eq. 2, this is expected to result in an equilibrium ionpair concentration, $n_{ \pm}=\sqrt{330 / 1.6 \times 10^{-6}}=14000 \mathrm{~cm}^{-3}$. In practice the mean ion concentration in the chamber will be smaller since ion losses other than ion-ion recombination have been ignored. In particular, diffusive losses of ions to the walls of the chamber are important, as well as ion scavenging by aerosols.

The experimental measurements are shown in Fig. 2 for the Gerdien counter. These data were recorded under low aerosol background conditions $\left(2-60 \mathrm{~cm}^{-3}\right.$, in a size range near the $3 \mathrm{~nm}$ detection threshold). The AIS measurements of positive ions were consistent with the Gerdien measurements, within experimental errors, but the AIS negative ion concentrations were measured at about half these values. This origin of this difference is not understood but it may have been due to an instrumental effect during the AIS setup period, when these data were recorded. During the remainder of the run, the mean positive and negative ion concentrations measured by the AIS generally differed by less than 


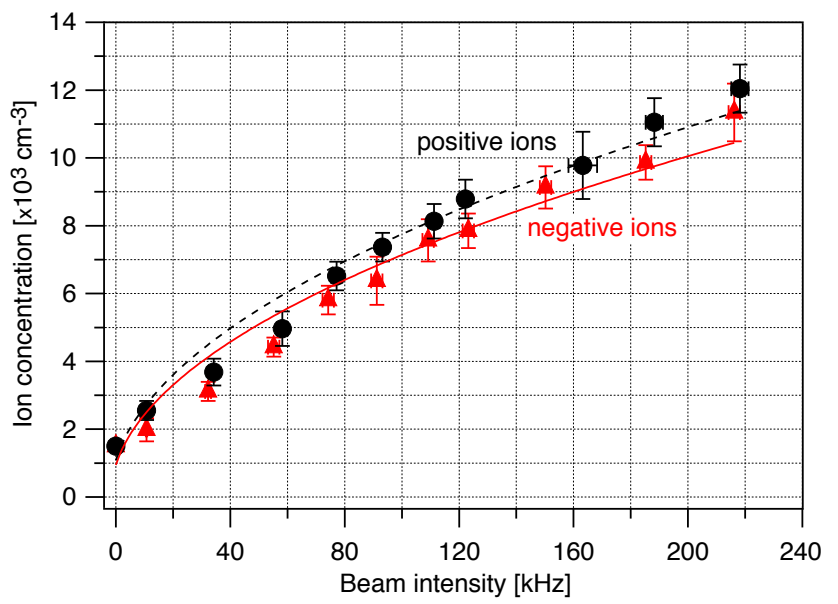

Fig. 2. Ion concentration in the chamber, measured with the Gerdien counter, as a function of beam intensity for i) positive ions (black circles and dashed curve) and ii) negative ions (red triangles and solid curve). The fitted curves are of the form $n_{ \pm}=k_{1} \sqrt{N_{b}+k_{0}}$, where $N_{b}$ is the time-averaged beam intensity and $k_{i}$ are free parameters. The finite ion concentrations at zero beam intensity are due to galactic cosmic rays.

$15 \%$. The simple estimates above are in good agreement with the Gerdien experimental data, namely ion-pair concentrations ranging from about $1500 \mathrm{~cm}^{-3}$ at zero beam to about $12000 \mathrm{~cm}^{-3}$ at the maximum, and a square root dependence on beam intensity.

\subsection{Nucleation events}

\subsubsection{Determination of nucleation and growth rates}

We used the size distribution from the AIS to calculate the formation and growth rates of charged particles. The AIS measures ions in the mobility diameter range $0.8-40 \mathrm{~nm}$, so we are able to detect the appearance of the newly formed particles at around $2 \mathrm{~nm}$ size (corresponding to near the critical size) and monitor their subsequent growth. An example of the AIS spectra is shown in the middle and upper panels of Fig. 3. Here the population of newly formed particles is taken to be those in the size range $2-3 \mathrm{~nm}$. The formation rate of charged aerosol particles at $2 \mathrm{~nm}$ size threshold, $J_{2}^{ \pm}$ $\left[\mathrm{cm}^{-3} \mathrm{~s}^{-1}\right.$ ], is given by (Kulmala et al., 2007)

$J_{2}^{ \pm}=\frac{d N_{2-3}^{ \pm}}{d t}+C S_{2} \times N_{2-3}^{ \pm}+\frac{G R}{1 \mathrm{~nm}} N_{2-3}^{ \pm}$

$+\alpha N_{2-3}^{ \pm} N_{<3}^{\mp}-\beta N_{2-3} N_{<3}^{\mp}$

where the superscript \pm refers to positively and negatively charged particles, respectively, the subscript $<3$ indicates particles below $3 \mathrm{~nm}$ diameter, $N_{2-3}\left[\mathrm{~cm}^{-3}\right]$ is the particle concentration in the $2-3 \mathrm{~nm}$ range, $C S_{2}\left[\mathrm{~s}^{-1}\right]$ is the coagulation sink rate for 2-nm particles (Kulmala et al., 2001), $G R$ $\left[\mathrm{nms}^{-1}\right]$ is the particle growth rate, $\alpha$ is the ion-ion recombination coefficient (Eq. 1), and $\beta\left[\mathrm{cm}^{3} \mathrm{~s}^{-1}\right]$ is the ion-neutral attachment coefficient.

Particle growth rates were determined from the AIS size spectra by finding the peak position in each channel of the AIS in the $2-5 \mathrm{~nm}$ region as a function of time, and then fitting a linear equation to these points. Further details of this method can be found in Hirsikko et al. (2005).

In the case of all aerosol particles (charged plus neutral), the formation rate of $3 \mathrm{~nm}$ particles, $J_{3}\left[\mathrm{~cm}^{-3} \mathrm{~s}^{-1}\right]$, is (Kulmala et al., 2007)

$J_{3}=\frac{d N_{3-4}}{d t}+C S_{3} \times N_{3-4}+\frac{G R}{1 \mathrm{~nm}} N_{3-4}$

Here, particle growth rates were determined from the CPCs. We assume that the coagulation sink losses with larger-sized particles are negligible since their concentrations were relatively low. Also, typical coagulation rates between $3 \mathrm{~nm}$ and, for example, $10 \mathrm{~nm}$ particles are around $10^{-8} \mathrm{~s}^{-1}$ and thus negligible. Therefore, the formation rate is simply

$J_{3}=\frac{d N_{>3}}{d t}$

\subsubsection{Overview of nucleation events}

During the 4-week run, 44 nucleation bursts were produced and recorded, with formation rates of particles above the $3 \mathrm{~nm}$ detection threshold of between 0.1 and $100 \mathrm{~cm}^{-3} \mathrm{~s}^{-1}$, and growth rates between 2 and $37 \mathrm{~nm} \mathrm{~h}^{-1}$. These values are similar to those observed in the atmosphere (Kulmala et al., 2004), e.g. growth rates of $1-2 \mathrm{nmh}^{-1}$ in the boreal forest (Dal Maso et al., 2005), and $40 \mathrm{nmh}^{-1}$ in Mexico City (Iida et al., 2008).

However the measured $\mathrm{H}_{2} \mathrm{SO}_{4}$ concentrations of around $10^{6} \mathrm{~cm}^{-3}$ or less were insufficient to support growth rates above $0.1 \mathrm{nmh}^{-1}$, and so additional condensable vapours must have been present in the chamber. Although their identity is unknown, organic vapours are suspected since the early runs showed strong nucleation bursts in association with high $\mathrm{O}_{3}$ concentrations, in the absence of UV light (see §4.1). This indicates the presence of organic vapours which are directly reacting with $\mathrm{O}_{3}$. Later runs under similar conditions produced no nucleation burst, indicating that the organic backgrounds had been substantially reduced. The cleaner conditions resulted from two improvements: 1) additional chamber flushing and cleaning and, perhaps more importantly, 2) replacing the de-ionised water in the humidifier with higher-purity water (Millipore Corporation). Although not directly measured, on the assumption that organic vapour contaminants were indeed responsible for the observed aerosol growth rates, we can estimate that their mixing ratios would need to be in the approximate range 120 pptv or larger (Joutsensaari et al., 2007).

The contribution of ion-induced nucleation to the aerosol bursts can be revealed in two independent ways: 1) the presence of a high fraction of charged aerosols in the event, and 

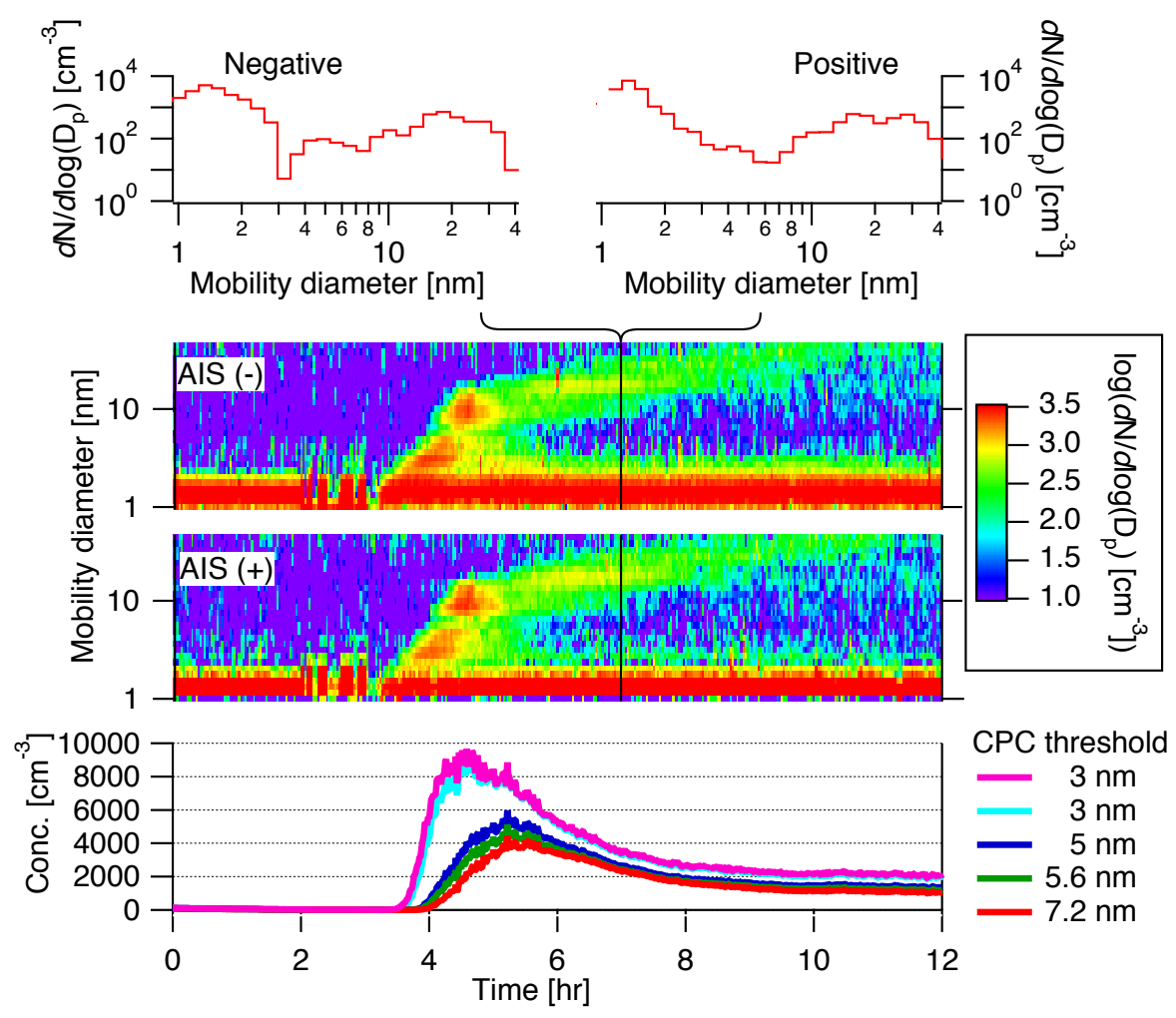

Fig. 3. An example (during run 15) of a nucleation burst in which ion processes are substantial. The time evolution is shown for particle size spectra measured by the CPC battery (bottom panel) and AIS (upper and middle panels for the negatively and positively charged particles, respectively). The CPCs record all neutral and charged aerosol particles, whereas the AIS records only charged aerosols and small ions. The upper histograms show size spectra of the negative (left) and positive (right) charged particles at 07:00. The aerosol size distributions are bi-modal, showing small ions and newly-formed particles below about $6 \mathrm{~nm}$, and aged particles from the nucleation burst at larger sizes.

2) association of a change of the beam intensity immediately followed by a change of formation rate, and a dependence of the formation rate on beam intensity. Each of these is discussed below.

\subsubsection{Events with a higher charged fraction}

The presence or absence of ion-induced nucleation can, in principle, be determined by measuring the charged vs. neutral fractions of the aerosol population as a function of size. Even in the absence of ion-induced nucleation, a finite charged fraction is expected due to diffusion charging of neutral aerosols by small ions. A characteristic of diffusion charging is that smaller aerosols have a lower charged fraction. For example, the Fuchs charging distribution predicts equilibrium charged fractions (both signs included) of 2.4, 4.1, and $19.7 \%$ for aerosols of diameter 3, 5, and $20 \mathrm{~nm}$, respectively, in a bipolar ion atmosphere (Keefe, Nolan and Rich, 1959; Wiedensohler, 1988; Willeke and Baron, 1993). Therefore the appearance of an "overcharged" aerosol distribution in the CPC battery - in which the charged aerosol fraction at $3 \mathrm{~nm}$ threshold is larger than at $7.2 \mathrm{~nm}$ threshold - is a fairly robust signature of ion-induced nucleation (Laakso et al., 2007). On the other hand, the absence of overcharging does not exclude contributions from ion-induced nucleation, since it may indicate either that the contribution is too small to be detected or else that the initially-charged aerosols have been partly neutralised by ion-aerosol attachment before reaching the $3 \mathrm{~nm}$ size threshold for measurement.

The electrostatic precipitator $(\$ 2.3)$ on the inlet line of the CPC battery allowed the charged fractions to be compared at $3 \mathrm{~nm}$ and $7.2 \mathrm{~nm}$, respectively. Of the 44 nucleation events analysed in the complete campaign, 6 were identified as overcharged - but the amount of overcharging was small in all cases. An example (run 15) is shown in Fig. 3. During this event, the total formation rate of 3-nm particles is $3.1 \mathrm{~cm}^{-3} \mathrm{~s}^{-1}$, and the charged aerosol growth rate at the start of the burst is $5.8 \mathrm{nmh}^{-1}$. The CPC battery measured a charged fraction of $6 \%$ for particles between $3 \mathrm{~nm}$ and $5 \mathrm{~nm}$, to be compared with an equilibrium charged fraction of below $4.1 \%$ (Wiedensohler, 1988). The latter figure is an over-estimate of the actual diffusion charge since the half time for diffusion charging under the conditions of this run is $12 \mathrm{~min}$ (Flanagan and O'Connor, 1961). In conclusion, 


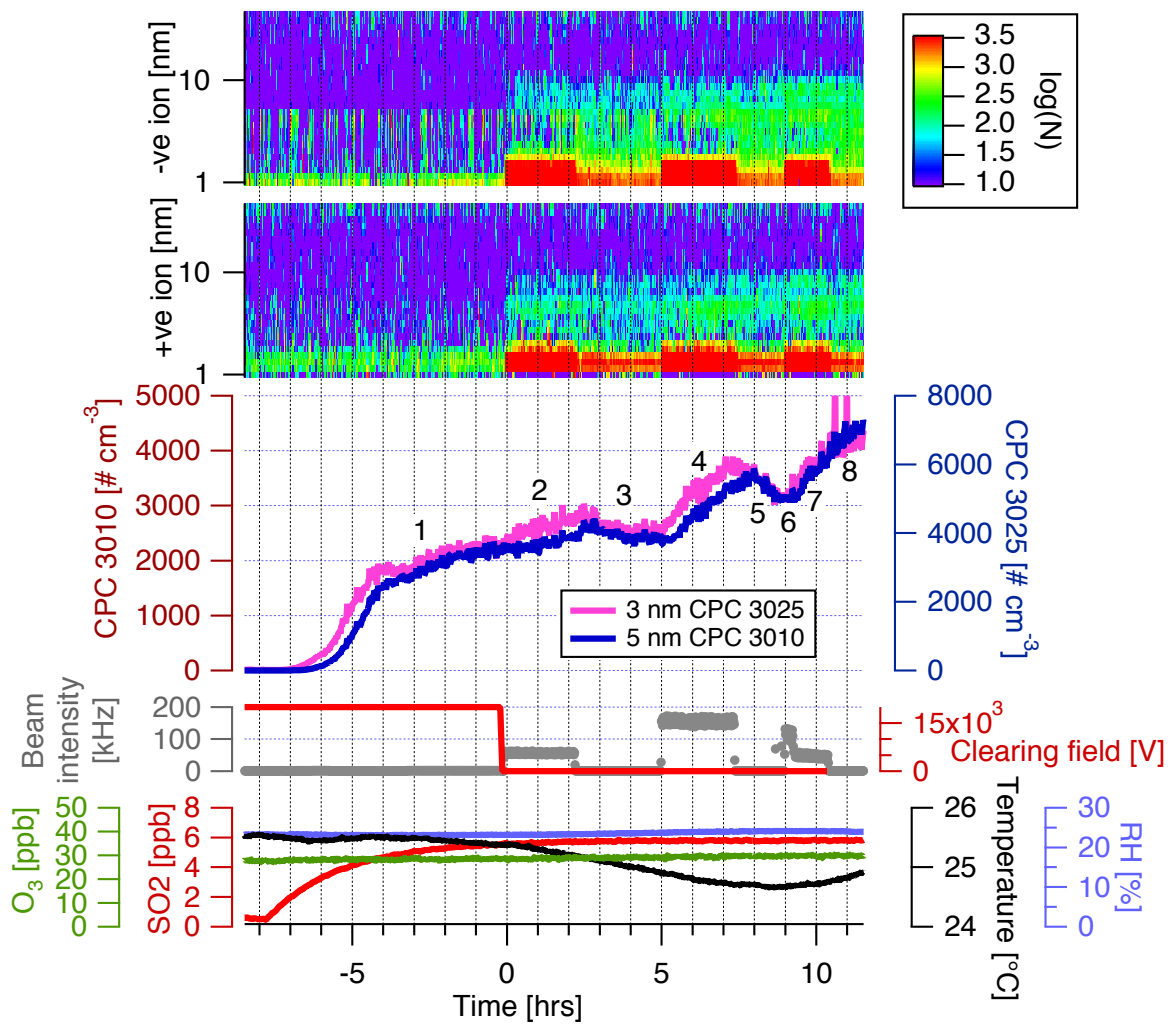

Fig. 4. Time evolution of run 35 (the final run of the campaign). A neutral nucleation burst begins about $7 \mathrm{~h}$ before the beam is first turned on at 00:00. Subsequently, the correlation of the beam hodoscope counts (grey curve) and the aerosol particle concentrations (magenta and blue CPC curves) suggests an additional component from ion-induced nucleation. A zoom of the measurements from the individual instruments in the CPC battery is shown in Fig. 5. The numbered regions correspond to the aerosol formation rate measurements summarised in Table 1.

direct measurements of the charged aerosol fraction suggest a small but finite contribution of ion-induced nucleation in some of the nucleation events.

\subsubsection{Beam-correlated nucleation events}

The second way to investigate the presence of ion-induced nucleation is to keep all conditions in the chamber constant except for a change of pion beam intensity, and to observe a change of formation rate such as the onset of an aerosol burst. This of course requires the absence - or at least a low rate of "spontaneous" aerosol bursts in the chamber. As will be described in $\$ 4.2$, spurious aerosol bursts were found to be generated by small temperature increases (of order $0.1^{\circ} \mathrm{C}$ ) of the chamber walls. This observation excludes from analysis all bursts observed in association with switching on the UV lights, since this transition always produced a substantial increase of wall temperatures (by up to $1^{\circ} \mathrm{C}$ ). For this reason, all the nucleation measurements reported here involve steady illumination with UV light $\left(2.4 \mathrm{~mW} / \mathrm{m}^{2}\right.$ at the $254 \mathrm{~nm}$ emission line). (For completeness, we remark that the pion beam has a negligible heating effect; at peak beam intensity the total thermal load on the chamber is of order $0.1 \mu \mathrm{W}$.)
The clearest example of an apparent time-association of beam transitions with aerosol nucleation events was obtained in the final run of the campaign (run 35). The time evolution of various parameters for this run is shown in Fig. 4. During the entire run 35 there were stable conditions for the following parameters: $\left[\mathrm{O}_{3}\right](28 \mathrm{ppb})$, relative humidity $(24 \%)$, and UV intensity $\left(2.1 \mathrm{mWm}^{-2}\right)$. Initially the particle concentration was low $\left(<25 \mathrm{~cm}^{-3}\right)$ but, as $\left[\mathrm{SO}_{2}\right]$ was raised from $0.6 \mathrm{ppb}$ to $6 \mathrm{ppb}$ a strong nucleation event occurred, producing several thousand particles per $\mathrm{cm}^{3}$. Since the clearing field was on during this interval (as can be inferred from the near-absence of small ions in the AIS data in Fig. 4), the initial aerosol burst involved only neutral nucleation. At the time when the clearing field was turned off, the particle concentration was $3600 \mathrm{~cm}^{-3}$. The beam was then immediately turned on for $2.4 \mathrm{~h}$ and the particle concentration increased to $4300 \mathrm{~cm}^{-3}$. (Again, the presence of beam can be inferred from the high concentration of small ions in the AIS data in Fig. 4.) The beam was then alternately turned off or on for periods of an hour or two, until the end of the run. The measured formation rates, $J_{3}$, are summarised in Table 1 and show a fair correlation with the beam intensity for regions 
Table 1. Particle formation rates for run 35 (the positive values are plotted in Fig. 8). The region numbers are shown in Figs. 4 and 5. The formation rates, $J_{3}$, correspond to the $3 \mathrm{~nm}$ threshold TSI 3025 CPC with a short sampling probe (magenta curve in Fig. 5). Negative values of $J_{3}$ signify a net sink of $3 \mathrm{~nm}$ particles.

\begin{tabular}{crcc}
\hline Region no. & $\begin{array}{r}\text { Start time } \\
{[\mathrm{h}]}\end{array}$ & $\begin{array}{c}\text { Beam intensity } \\
{[\mathrm{kHz}]}\end{array}$ & $\begin{array}{c}\text { Formation rate, } J_{3} \\
{\left[\mathrm{~cm}^{-3} \mathrm{~s}^{-1}\right]}\end{array}$ \\
\hline 1 & $-06: 30$ & 0 & $0.064 \pm 0.002$ \\
2 & $00: 00$ & 58 & $0.083 \pm 0.004$ \\
3 & $02: 20$ & 0 & $-0.571 \pm 0.005$ \\
4 & $05: 09$ & 158 & $0.223 \pm 0.006$ \\
5 & $07: 34$ & 0 & $-0.163 \pm 0.009$ \\
6 & $09: 12$ & 116 & $0.400 \pm 0.030$ \\
7 & $09: 30$ & 50 & $0.133 \pm 0.046$ \\
8 & $10: 39$ & 0 & $0.076 \pm 0.015$ \\
\hline
\end{tabular}

2 to 6 , when conditions were most stable (ie. $\left[\mathrm{SO}_{2}\right]$ constant and temperature not increasing). The modulation pattern in Fig. 4 suggests a contribution at around the $10 \%$ level from ion-induced nucleation, in addition to the dominant neutral nucleation.

The detailed time evolution of each instrument in the CPC battery during this run is shown in Fig. 5. The 3-nm CPCs respond rapidly to beam transitions whereas the 5, 5.6 and 7.2$\mathrm{nm}$ CPCs show a progressively delayed response, as would be expected if the formation rate of new aerosol particles were being alternately decreased and increased. The final transition to beam-off (region 8) occurred during an increase of temperature of the chamber and so is subject to spurious nucleations. With the exclusion of this last transition, there is a good time-correlation of beam changes with formation-rate changes.

Although run 35 shows a time-correlation that suggests the presence of ion-induced nucleation, there is no evidence for this from the measurements of charged fraction. As described in $\$ 3.2 .3$, this does not rule out the possibility of ioninduced nucleation, but neither does it add support. In addition, ion-ion recombination rates at the highest beam intensities are above $200 \mathrm{~cm}^{-3} \mathrm{~s}^{-1}$ and so recombination is also a candidate mechanism for new particle formation, provided that the neutral clusters formed by the recombination exceed the critical size.

We can rule out the possibility that the beam-related nucleation seen in Figs. 4 and 5 is due to radical chemistry caused by the particle beam. The estimated production of radicals by the particle beam is $2 \mathrm{OH}_{\mathrm{x}}$ molecules per ion pair (Solomon et al., 1981) and $1.0 \mathrm{NO}_{\mathrm{x}}$ molecule per ion pair (Nicolet, $1975)$. The highest intensity beam rate $(220 \mathrm{kHz})$ produces a mean ionisation rate, $330 \mathrm{~cm}^{-3} \mathrm{~s}^{-1}(\$ 3.1)$. The corresponding production rates of $\mathrm{OH}_{\mathrm{x}}$ and $\mathrm{NO}_{\mathrm{x}}$ are therefore $660 \mathrm{~cm}^{-3} \mathrm{~s}^{-1}$ and $330 \mathrm{~cm}^{-3} \mathrm{~s}^{-1}$, respectively. These rates are negligible in comparison with the estimated $10^{5} \mathrm{~cm}^{-3} \mathrm{~s}^{-1}$

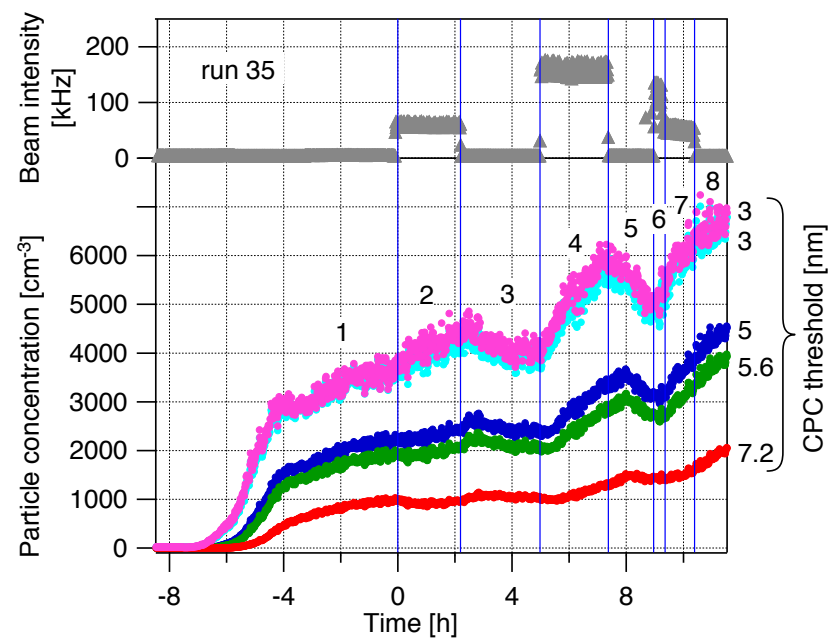

Fig. 5. Detailed time evolution of each instrument in the CPC battery during the run shown in Fig. 4 (lower panel). The aerosol concentrations appear to respond to the changes of beam intensity (upper panel), with the expected delayed response for the higherthreshold CPCs.

production rate of $\mathrm{OH}$ from $\mathrm{O}_{3}$ photolysis $\left(2.2 \mathrm{~mW} / \mathrm{m}^{2}\right.$ at the $254 \mathrm{~nm}$ emission line).

Other runs taken under conditions similar to run 35 show either weak or even contradictory evidence for ion-induced nucleation. An example of the latter is presented in Fig. 6, which shows the time evolution of run 28. At 02:12 the beam was turned on at $100 \mathrm{kHz}$ rate, which, from Eq. 4, produces in the chamber a mean ionisation rate, $Q_{b}=150 \mathrm{~cm}^{-3} \mathrm{~s}^{-1}$. However, only a mild increase was observed in the particle concentration: $40 \mathrm{~cm}^{-3}$ over a two-hour period, corresponding to a formation rate of about $0.01 \mathrm{~cm}^{-3} \mathrm{~s}^{-1}$. These figures place quite a strong limit against ion-induced nucleation in this event.

Figure 7 summarises the measurements of formation rate versus beam intensity for all runs taken under similar cleanchamber conditions during the last week of the campaign. Most of these measurements show no correlation with beam intensity, but do show a strong dependence of formation rate on $\left[\mathrm{SO}_{2}\right]$, indicating that sulphuric species are a dominant component of the observed nucleation. The measurements taken at $6 \mathrm{ppb}\left[\mathrm{SO}_{2}\right]$ may indicate some dependence of formation rate on beam intensity (Fig. 8). However, even at these relatively high $\mathrm{SO}_{2}$ concentrations, the formation rate was well below $1 \mathrm{~cm}^{-3} \mathrm{~s}^{-1}$ at beam ionisation rates (Eq. 4) in the range $70-240$ i.p. $\mathrm{cm}^{-3} \mathrm{~s}^{-1}$. So the $6 \mathrm{ppb}\left[\mathrm{SO}_{2}\right]$ measurements all show a very low ratio of formation rate per ion pair created in the chamber (roughly $10^{-3}$ ). There are two possible reasons for this: either ion nucleation effects are simply unimportant or else - even at $6 \mathrm{ppb}\left[\mathrm{SO}_{2}\right]$ - the experimental $\mathrm{H}_{2} \mathrm{SO}_{4}$ concentration was still too low to allow significant ion-induced nucleation to occur. 


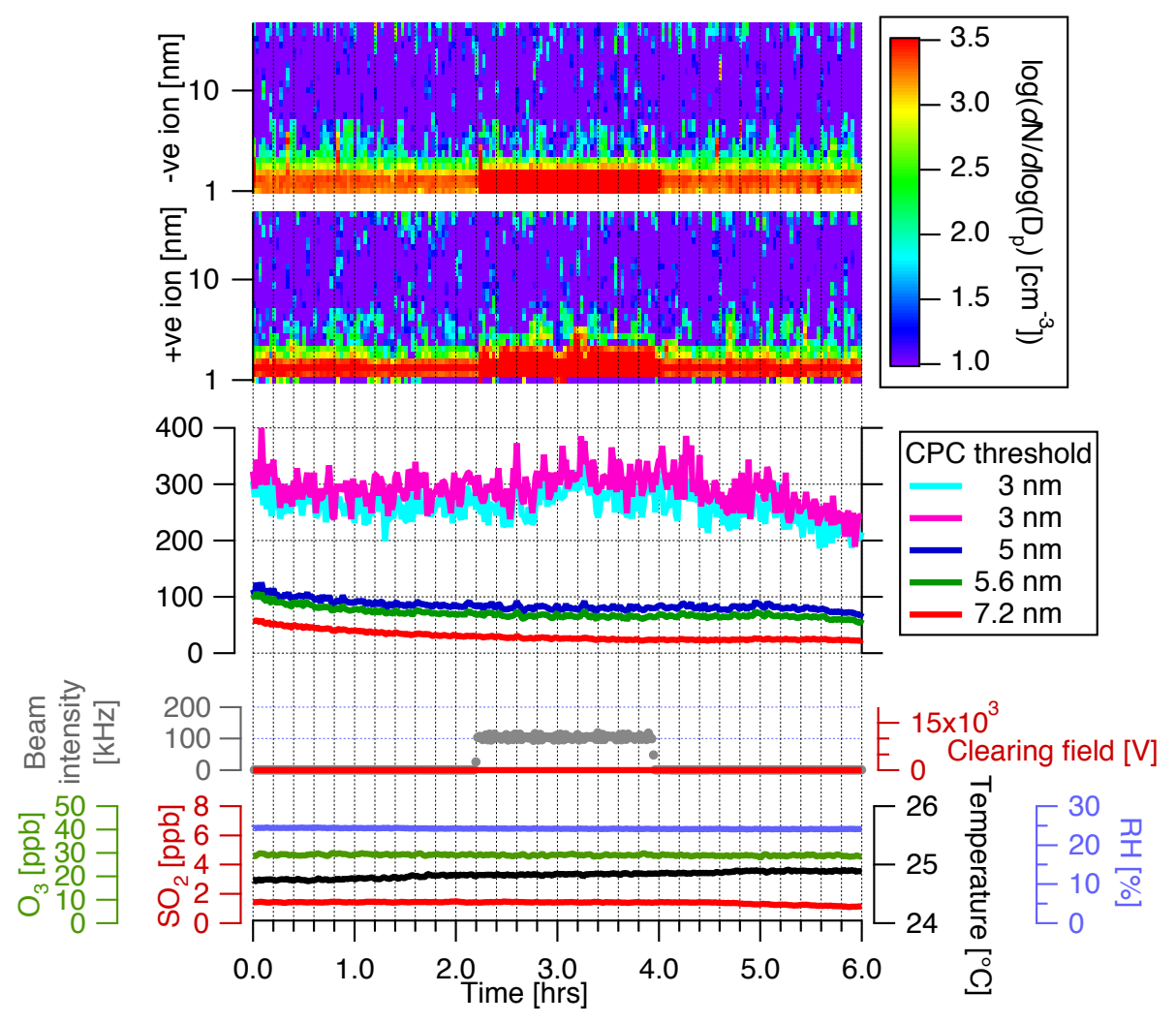

Fig. 6. Time evolution of run 28. At $2 \mathrm{~h} 12$ the $\pi^{+}$beam was turned on at $100 \mathrm{kHz}$ rate (grey curve). However only a mild increase was observed in the particle concentration (magenta and cyan curves in the centre panel), indicating negligible ion-induced nucleation. The other chamber conditions (including UV intensity, which is not shown) remained steady throughout this run.

Unfortunately, since the CIMS was not present for these final days of data, no simultaneous $\left[\mathrm{H}_{2} \mathrm{SO}_{4}\right]$ measurements are available. However, by scaling the early CIMS measurements, we estimate that the $6 \mathrm{ppb}\left[\mathrm{SO}_{2}\right]$ data correspond to $\left[\mathrm{H}_{2} \mathrm{SO}_{4}\right] \sim 10^{6} \mathrm{~cm}^{-3}$, with a large estimated uncertainty of a factor 3. Our results are therefore consistent with previous atmospheric and laboratory nucleation measurements of $\mathrm{SO}_{2}$ photonucleation, which is observed to occur in the $\mathrm{H}_{2} \mathrm{SO}_{4}$ concentration range, $10^{5}-10^{7} \mathrm{~cm}^{-3}$ (see Fig. 2 in Laaksonen et al. (2008)).

In conclusion, therefore, the experimental variables were not well enough controlled to exclude the presence of ioninduced nucleation on the basis of Fig. 7; it merely does not support the presence of strong contributions from this source. Indeed, at $6 \mathrm{ppb}\left[\mathrm{SO}_{2}\right]$, there are some indications of a dependence of formation rate on beam intensity. In addition to poorly-defined $\mathrm{H}_{2} \mathrm{SO}_{4}$ concentrations, among the most important uncertainties is the influence of background organic vapours, as described in the next section.

\section{Technical lessons for the cloud design}

\subsection{Chamber cleanliness}

In the early part of the 4-week experimental run, the aerosol bursts were characterised by large peak concentrations $\left(>10000 \mathrm{~cm}^{-3}\right)$, relatively high formation rates $\left(>10 \mathrm{~cm}^{-3} \mathrm{~s}^{-1}\right)$ and rapid growth $\left(>10 \mathrm{nmh}^{-1}\right)$. As the run progressed and the chamber became cleaner, the aerosol bursts were significantly less intense.

The chamber was progressively cleaned by two methods: 1) continual flushing with humidified ultrapure air, and 2) cleaning cycles involving temporarily high ozone concentrations in the presence of UV light. Throughout the experiment, the air flow rate was maintained near $50 \mathrm{l} / \mathrm{min}$. This corresponds to 9 chamber volumes per day, which is equivalent to a dilution of gaseous impurities in the chamber by a factor of about $e^{9}=10^{4}$ per day. In practice, since contaminants were continually desorbing from the inner surfaces of the chamber, the rate of decrease of chamber contaminants is expected to be much slower than this. Sources of contaminants include the stainless steel walls and field cage electrodes, and organic materials such as the field cage insulators, 


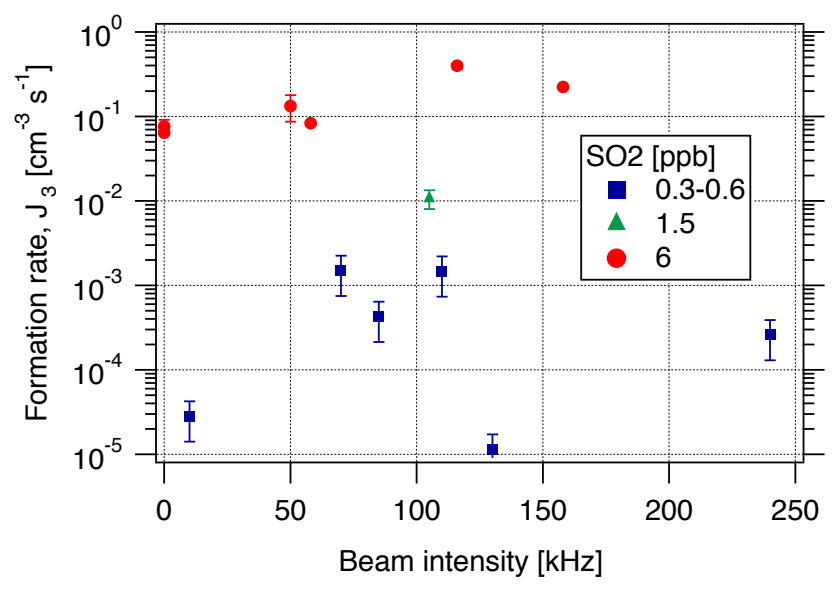

Fig. 7. Particle formation rate, $J_{3}$, vs. beam intensity for several $\mathrm{SO}_{2}$ concentrations. Where the error bars are not seen, they are smaller than the size of the data points. Although the data show no correlation with beam intensity - with the exception of the measurements taken at $6 \mathrm{ppb}\left[\mathrm{SO}_{2}\right]$ (see Fig. 8) - the experimental variables (such as $\left[\mathrm{H}_{2} \mathrm{SO}_{4}\right]$ and background organic vapours) were not well enough controlled to exclude the presence of ion-induced nucleation on the basis of this plot.

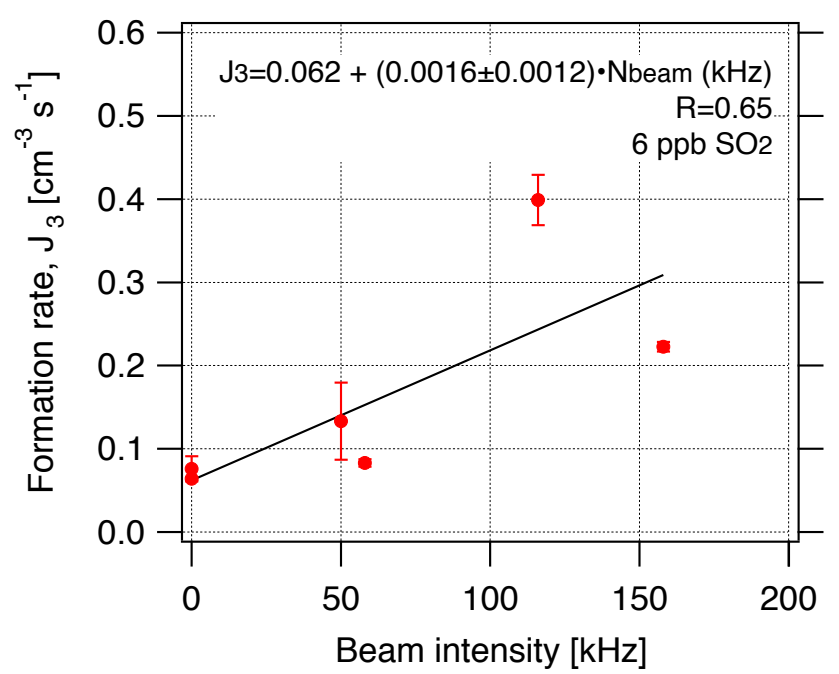

Fig. 8. Particle formation rate, $J_{3}$, vs. beam intensity, at $6 \mathrm{ppb}$ $\left[\mathrm{SO}_{2}\right]$. The measurements are listed in Table 1 ("negative" formation rates - corresponding to aerosol particle sinks - are not plotted).

the silicone $\mathrm{O}$ ring seals, the PTFE window and its sealing tape. Nevertheless, a steady reduction of contaminants was inferred from the gradually decreasing intensity of the nucleation bursts and the very low levels of background particles that were eventually achieved (well below $1 \mathrm{~cm}^{-3}$ ).

The improving cleanliness of the chamber was also directly inferred from the ozone cleaning cycles. At the beginning of the run, 5 tests were made with $\left[\mathrm{O}_{3}\right]$ in the range 100
$450 \mathrm{ppb}$ and with the UV lights off. Each of these elevated ozone levels caused large nucleation bursts, with peak formation rates of $10 \mathrm{~cm}^{-3} \mathrm{~s}^{-1}$ and peak concentrations in the range $1000-17000 \mathrm{~cm}^{-3}$. No correlation was observed between the peak aerosol concentration and $\left[\mathrm{O}_{3}\right]$. These observations suggest the presence of condensable organic vapours in the chamber. In contrast, later in the cycle, a similar test was performed with $440 \mathrm{ppb}\left[\mathrm{O}_{3}\right]-$ a factor of 15 higher than the nominal $\mathrm{O}_{3}$ concentration - and no nucleation was observed. This implies a substantial reduction of organic contaminants.

Sulphur dioxide was added to the chamber only in the final days of the run. Prior to the addition of $\mathrm{SO}_{2}$, the concentration in the chamber was measured to be steady between 0.1 and $0.2 \mathrm{ppb}$. The source of the $\mathrm{SO}_{2}$ was not determined, but is likely to be desorption from the inner walls of the chamber, which had been exposed to atmospheric air prior to assembly. Some evidence to support this was provided by observations early in the run of increases of $\left[\mathrm{SO}_{2}\right]$ by $0.1-0.2 \mathrm{ppb}$ in coincidence with wall temperature increases. No correlation was observed between the intensity of the nucleation bursts and $\left[\mathrm{SO}_{2}\right]$ in the range $0.1-0.2 \mathrm{ppb}$. However, when $\left[\mathrm{SO}_{2}\right]$ was raised in the final days of the run, a strong correlation was observed (Fig. 7), but was not well characterised due to lack of time. The final data of the run were taken at $6 \mathrm{ppb}\left[\mathrm{SO}_{2}\right]$.

There are several lessons from these observations for the CLOUD design. Firstly, the control and measurement of organic vapours is crucial for these experiments - not only as a potential source of backgrounds but also as a participant in the aerosol nucleation and growth processes. Secondly, the chamber components must be carefully designed and prepared to stringent standards of cleanliness, following procedures developed for ultra high vacuum equipment. This has implications both on the selection of any material exposed to the chamber volume and also on the preparation and cleaning of the inner surfaces of the chamber and gas system. In addition, a cleaning procedure is required for the chamber between runs, including, for example, a heating and high-flush-rate cycle in the presence of UV and ozone to evaporate, oxidise and exhaust volatile surface contaminants. Concerning the generation of ultrapure air from cryogenic liquids, no contaminants were detected and so this system will be retained in the CLOUD design. This observation is, however, qualified by the limited instrumentation available for the 2006 experiment. Nevertheless, it is reassuring that - despite the relatively crude levels of cleanliness of the 2006 chamber - extremely clean experimental conditions were eventually achieved in terms of background aerosol particles $\left(N_{3} \ll 1 \mathrm{~cm}^{-3}\right)$ and $\left[\mathrm{H}_{2} \mathrm{SO}_{4}\right]\left(\ll 10^{6} \mathrm{~cm}^{-3}\right)$.

\subsection{Temperature stability}

During the first half of the experimental run, there was no temperature control of the aerosol chamber. The chamber therefore followed the ambient temperature of the 


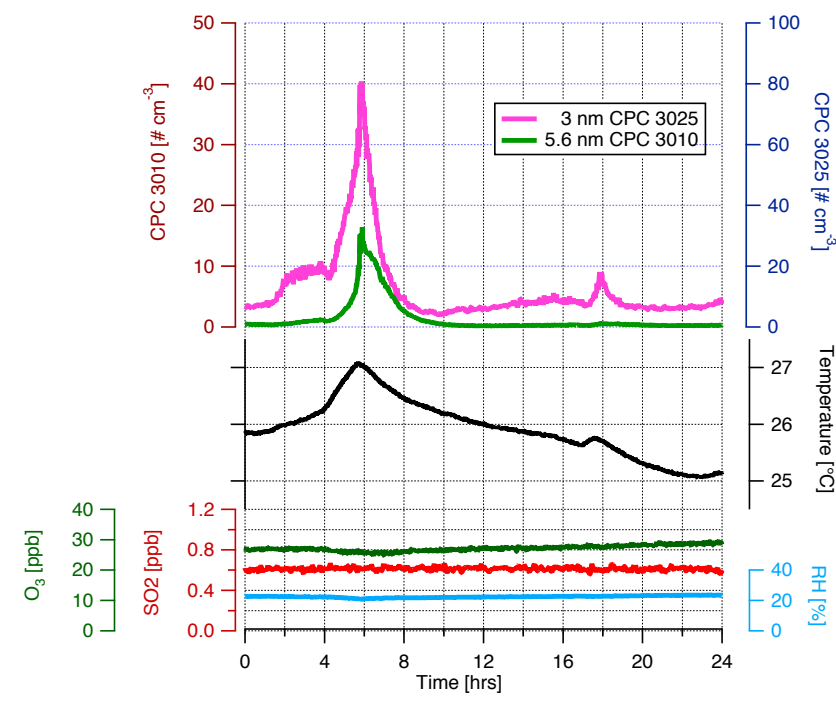

Fig. 9. Examples during runs 32 and 33 of two nucleation bursts (magenta and green curves in the top panel) caused by small increases of the wall temperature of the aerosol chamber (black curve in centre panel).

experimental hall, and the wall temperature varied in the range $20-28^{\circ} \mathrm{C}$. In the second half of the run, a simple airconditioned insulated housing was installed. This considerably improved the temperature stability, but diurnal variations of about $\pm 1{ }^{\circ} \mathrm{C}$ remained about a mean value near $25^{\circ} \mathrm{C}$.

An important observation was made from these environmentally-induced temperature changes of the chamber: a small rise of wall temperature over a short time interval almost always gave rise to a spontaneous burst of freshly-nucleated particles. Two examples, during runs 32 and 33, are shown in Fig. 9. Bursts were observed for temperature increases as small as $0.1{ }^{\circ} \mathrm{C}$ over a $15 \mathrm{~min}$ period. On the other hand, temperature decreases did not give rise to aerosol bursts. The bursts could be unambiguously associated with wall temperature increases since no other parameters of the experiment were changed at the time of their occurrence.

Although the underlying cause of these spurious aerosol bursts was not unambiguously determined, the most likely candidate is that the temperature rise caused trace vapours (sulphur dioxide, sulphuric acid and/or organic compounds) to be released from the walls of the chamber and then nucleation occurred in the resultant relatively high vapour concentrations created in the boundary layer adjacent to the walls. Measurements during the early stage of the run - when the chamber was less clean - did indeed show evidence of increases of $\left[\mathrm{SO}_{2}\right]$ during temperature increases.

An important consequence of this observation concerns the UV burst data, i.e. measurements of aerosol production following a brief exposure of UV light for a few minutes. The UV bursts are designed to generate a brief and limited production of $\mathrm{H}_{2} \mathrm{SO}_{4}$ in the chamber, to allow nucleation bursts to be studied under steady-state conditions of other parameters, such as ionisation rate. For practical UV intensities, these brief exposures of UV light always produced a temperature increase of the chamber wall, with a gradient of about $0.1^{\circ} \mathrm{C}$ per $10 \mathrm{~min}$. Since stable temperature conditions were not met for UV bursts during the pre-CLOUD experiment, we have not used UV burst data for quantitative studies presented in this work, to avoid spuriously-generated nucleations.

The lesson from these observations for the CLOUD design is that a UV system is required that provides a negligible thermal load on the chamber. The bank of UV lights for the pilot CLOUD chamber generated a thermal output of $525 \mathrm{~W}$ to provide a UV power of less than $300 \mathrm{~mW}$ in the chamber, so there is room for a large improvement. A new UV fibre optic system has been designed which delivers a higher UV power to the CLOUD chamber, with no parasitic thermal load.

\section{Conclusions}

Initial measurements have been made with a pilot CLOUD experiment at the CERN Proton Synchrotron. The accelerator beam generated equilibrium ion-pair concentrations in the aerosol chamber of between one and ten times the atmospheric values at ground level, which corresponds to between one and almost a hundred times the intensity of galactic cosmic rays. Experimental measurements in the presence of low aerosol backgrounds confirmed a dependence of equilibrium ion-pair concentrations on the square root of the beam intensity, as expected when the dominant loss mechanism is ion-ion recombination.

During the 4-week run, around 50 nucleation bursts were produced and recorded, with typical formation rates of particles above the $3 \mathrm{~nm}$ detection threshold of about 1$10 \mathrm{~cm}^{-3} \mathrm{~s}^{-1}$, and growth rates of $5-20 \mathrm{~nm} \mathrm{~h}^{-1}$. Concentrations of $\mathrm{H}_{2} \mathrm{SO}_{4}$ were experimentally measured with a chemical ionisation mass spectrometer to be around $10^{6} \mathrm{~cm}^{-3}$ or less. The large observed growth rates indicate the presence of additional trace vapours in the aerosol chamber, whose identity is unknown but for which there is indirect evidence of background organic vapours. The presence of background vapours is also inferred from the observation that small (of order $0.1^{\circ} \mathrm{C}$ ) increases of temperature invariably trigger nucleation bursts, which is attributed to the release of unknown vapours from the chamber walls.

Interestingly we were able to observe different kinds of new particle formation events. A few of the events appear to be related to ion-induced nucleation or ion-ion recombination to form stable neutral clusters. In these cases, a small but significant fraction of new particle formation could be explained by ion processes. However, during most nucleation 
events, the contribution of ion processes appeared to be minor. The accelerator beam was also used to search for timecorrelated nucleation bursts in the chambers. These revealed some evidence for a dependence of particle formation on beam intensity at the highest $\mathrm{SO}_{2}$ concentrations of $6 \mathrm{ppb}$, although no evidence was found at lower concentrations.

In summary, the exploratory measurements made with a pilot CLOUD experiment at the CERN Proton Synchrotron have validated the basic concept of the experiment, provided valuable technical input for the CLOUD design and instrumentation, and provided, in some of the experiments, suggestive evidence for ion-induced nucleation or ion-ion recombination as sources of aerosol particles from trace sulphuric acid vapour at typical atmospheric concentrations.

Acknowledgements. We would like to thank CERN for its support of the experiment and for the efficient operation of the Proton Synchrotron. We would also like to thank the staff of Pharma Steel, Copenhagen, for their contributions to the design and construction of the aerosol chamber under project DAN 635. J. D. is supported by the European Community under the FP7 Marie Curie Initial Training Network “CLOUD-ITN” (PITN-GA-2008-215072).

Edited by: M. Petters

\section{References}

Aplin, K. L. and Harrison, R. G.: A computer-controlled Gerdien atmospheric ion counter, Rev. Sci. Instrum., 71(8), 3037-3041, 2000.

Asmi, E., Sipilä, M., Manninen, H. E. , Vanhanen, J., Lehtipalo, K., Gagné, S., Neitola, K., Mirme, A., Mirme, S., Tamm, E., Uin, J., Komsaare, K., Attoui, M., and Kulmala, M.: Results of the first air ion spectrometer calibration and intercomparison workshop, Atmos. Chem. Phys., 9, 141-154, 2009,

http://www.atmos-chem-phys.net/9/141/2009/.

Bricard, J., Billard, F., and Madelain, G.: Formation and evolution of nuclei of condensation that appear in air initially free of aerosols, J. Geophys. Res., 73, 4487-4496, 1968.

Carbagas, Gümligen, Switzerland, available online at: http://www. carbagas.ch/, 2009.

Carslaw, K. S., Harrison, R. G., and Kirkby, J.: Cosmic rays, clouds, and climate, Science, 298, 1732-1737, 2002.

CLOUD Collaboration: A study of the link between cosmic rays and clouds with a cloud chamber at the CERN PS, CERNSPSC-2000-021, CERN-SPSC-2000-030, CERN-SPSC-2000041, available online at: http://cloud.web.cern.ch/cloud/, 2000.

Curtius, J., Sierau, B., Arnold, F., Baumann, R., Busen, R., Schulte, P., and Schumann, U.: First direct sulphuric acid detection in the exhaust plume of a jet aircraft in flight, Geophys. Res. Lett., 25, 923-926, 1998.

Dal Maso, M., Kulmala, M., Riipinen, I., Wagner, R., Hussein, T., Aalto, P. P., and Lehtinen, K. E. J.: Formation and growth of fresh atmospheric aerosols: eight years of aerosol size distribution data from SMEAR II, Hyytiälä, Finland, Boreal Env. Res., 10, 323336, 2005.

Eichkorn, S., Wilhelm, S., Aufmhoff, H., Wohlfrom, K. H., and Arnold, F.: Cosmic ray-induced aerosol-formation: First ob- servational evidence from aircraft-based ion mass spectrometer measurements in the upper troposphere, Geophys. Res. Lett., 29, 1698, 43.1-43.4, 2002.

Enghoff, M. B. and Svensmark, H., The role of atmospheric ions in aerosol nucleation - a review, Atmos. Chem. Phys., 8, 49114923, 2008, http://www.atmos-chem-phys.net/8/4911/2008/.

Enghoff, M. B., Pedersen, J. O. P., Bondo, T., Johnson, M. S., Paling, S., and and Svensmark, H.: Evidence for the role of ions in aerosol nucleation, J. Phys. Chem., A, 112, 10305-10309, 2008.

Flanagan, V. P. V. and O'Connor, T. C.: Ionization equilibrium in aerosols, Pure App. Geophys., 50, 148-154, 1961.

Gerdien, H.: Demonstration eines Apparates zur absoluten Messung der elektrischen Leitfähigheit der Luft, Phys. Zeitung, 6, 800-801, 1905.

Hermann, M., Adler, S., Caldow, R., Stratmann, F., and Wiedensohler, A.: Pressure-dependent efficiency of a condensation particle counter operated with FC-43 as working fluid, J. Aerosol Sci., 36, 1322-1337, 2005.

Hirsikko, A., Laakso, L., Hörrak, U., Aalto, P. P., Kerminen, V.M., and Kulmala, M.: Annual and size dependent variation of growth rates and ion concentrations in boreal forest, Boreal Env. Res., 10, 357-369, 2005.

Iida, K., Stolzenburg, M. R., McMurry, P. H., and Smith, J. N. Estimating nanoparticle growth rates from size-dependent charged fractions: analysis of new particle formation events in Mexico City, J. Geophys. Res., 113, D05207, doi:10.1029/2007JD009260, 2008.

IPCC, Climate Change 2007: the Physical Science Basis. Contribution of Working Group I to the Fourth Assessment Report of the Intergovernmental Panel on Climate Change, Cambridge University Press, 2007.

Joutsensaari, J., Loivamäki, M., Vuorinen, T., Miettinen, P., Nerg, A.-M., Holopainen, J. K., and Laaksonen, A.: Nanoparticle formation by ozonolysis of inducible plant volatiles, Atmos. Chem. Phys., 5, 1489-1495, 2005,

http://www.atmos-chem-phys.net/5/1489/2005/.

Kazil, J., Lovejoy, E. R., Barth, M. C., and O’Brien, K.: Aerosol nucleation over oceans and the role of galactic cosmic rays, Atmos. Chem. Phys., 6, 4905-4924, 2006, http://www.atmos-chem-phys.net/6/4905/2006/.

Kazil, J., Harrison, R. G., and Lovejoy, E. R.: Tropospheric new particle formation and the role of ions, Sp. Sci. Rev., 137, 241255, 2008.

Keefe, D., Nolan, P. J., and Rich, T. A.: Charge equilibrium in aerosols according to the Boltzmann law, Proc. Royal Irish Acad., 60, 27-45, 1959.

Kirkby, J.: Cosmic rays and climate, Surv. Geophys., 28, 333-375, 2007.

Kulmala, M., Dal Maso, M., Mäkelä, J. M., Pirjola, L., Väkevä, M., Aalto, P. P., Miikkulainen, P., Hämeri, K., and O’Dowd, C. D.: On the formation, growth and composition of nucleation mode particles, Tellus 53B, 479-490, 2001.

Kulmala, M., Vehkamäki, H., Petäjä, T., Dal Maso, M., Lauri, A., Kerminen, V.-M., Birmili, W., and McMurry, P. H.; Formation and growth rates of ultrafine atmospheric particles: A review of observations, J. Aerosol Sci. 35, 143-176, 2004.

Kulmala, M., Riipinen, I., Sipilä, M., Manninen, H. E., Petäjä, T., Junninen, H., Dal Maso, M., Mordas, G., Mirme, A., Vana, M., Hirsikko, A., Laakso, L., Harrison, R. M., Hanson, I., Le- 
ung, C., Lehtinen, K. E. J., and Kerminen, V.-M.: Toward direct measurement of atmospheric nucleation, Science, 318, 89-92, 10.1126/science.1144124, 2007.

Laakso, L., Gagné, S., Petäjä, T., Hirsikko, A., Aalto, P. P., Kulmala, M., and Kerminen, V.-M.: Detecting charging state of ultra-fine particles: instrumental development and ambient measurements, Atmos. Chem. Phys., 7, 1333-1345, 2007, http://www.atmos-chem-phys.net/7/1333/2007/.

Laaksonen, A., Kulmala, M., Berndt, T., et al.: $\mathrm{SO}_{2}$ oxidation products other than $\mathrm{H}_{2} \mathrm{SO}_{4}$ as a trigger of new particle formation. Part 2: Comparison of ambient and laboratory measurements, and atmospheric implications, Atmos. Chem. Phys., 8, 7255-7264, 2008, http://www.atmos-chem-phys.net/8/7255/2008/.

Lee, S. H., Reeves, J. M., Wilson, J. C., Hunton, D. E., Viggiano, A. A., Miller, T. M., Ballenthin, J. O., and Lait, L. R.: Particle formation by ion nucleation in the upper troposphere and lower stratosphere, Science, 301, 1886-1889, 2003.

Lockwood, M. and Fröhlich, K.: Recent oppositely directed trends in solar climate forcings and the global mean surface air temperature, Proc. Roy. Soc. A, doi:10.1098/rspa.2007.1880, 24472460, 2007.

Lovejoy, E. R., Curtius, J., and Froyd, K. D.: Atmospheric ioninduced nucleation of sulfuric acid and water, J. Geophys. Res., 109, D08204, doi:10.1029/2003JD004460, 2004.

Millipore Corporation, Massachusetts, USA, available online at: http://www.millipore.com/index.do/, 2009.

Mirme, A., Tamm, E., Mordas, G., Vana, M., Uin, J., Mirme, S., Bernotas, T., Laakso, L., Hirsikko, A., and Kulmala, M.: A wide range multi-channel Air Ion Spectrometer, Boreal Env. Res., 12, 247-264, 2007.

Möhler, O., and Arnold, F.: Gaseous sulfuric-acid and sulfurdioxide measurements in the Arctic troposphere and lower stratosphere - implications for hydroxyl radical abundances, Berichte Der Bunsen-Gesellschaft, Phys. Chem. Chem. Phys., 96, 3, 280 283, 1992.

Nicolet, M.: On the production of nitric oxide by cosmic rays in the mesosphere and stratosphere, Planet. Space Sci., 23, 637-649, 1975.

Pierce, J. R. and Adams, P. J.: Can cosmic rays affect cloud condensation nuclei by altering new particle formation rates?, Geophys. Res. Lett., 36, L09820, doi:10.1029/2009GL037946, 2009.

Reiner, T., and Arnold, F.: Laboratory investigations of gaseous sulfuric acid formation via $\mathrm{SO}_{3}+\mathrm{H}_{2} \mathrm{O}+\mathrm{M} \rightarrow \mathrm{H}_{2} \mathrm{SO}_{4}+\mathrm{M}$ : measurement of the rate constant and products identification, J. Chem. Phys., 101, 7399-7407, 1994.
Siingh, D.: Cosmic rays and Earth's atmospheric processes: a review, Earth Science India, 1, 108-134, 2008.

Smirnov, I.: Modeling of ionization produced by fast charged particles in gases, Nucl. Inst. Meth. A 554, 474-493, 2005.

Solomon, S., Rusch, D. W., Gérard, J.-C., Reid, G. C., and Crutzen, P. J.: The effect of particle precipitation events on the neutral and ion chemistry of the middle atmosphere: II. Odd hydrogen, Planet. Space Sci., 29, 8, 885-893, 1981.

Svensmark, H. and Friis-Christensen, E.: Variation of cosmic ray flux and global cloud coverage - A missing link in solar-climate relationships, J. Atm. Sol. Terr. Phys., 59, 1225-1232, 1997.

Svensmark, H., Pedersen, J. O. P., Marsh, N. D., Enghoff, M. B., and Uggerhøj, U. I.: Experimental evidence for the role of ions in particle nucleation under atmospheric conditions, Proc. Roy. Soc. A, 463, 385-396, 2007.

Tammet, H. and Kulmala, M.: Simulation tool for atmospheric aerosol nucleation bursts, J. Aerosol Sci., 36, 173-196, 2005.

Tammet, H., Hõrrak, U., Laakso, L., and Kulmala, M.: Factors of air ion balance in a coniferous forest according to measurements in Hyytiälä, Finland, Atmos. Chem. Phys., 6, 3377-3390, 2006, http://www.atmos-chem-phys.net/6/3377/2006/.

Usoskin, I. G. and Kovaltsov, G. A.: Cosmic ray induced ionization in the atmosphere: Full modeling and practical applications, J. Geophys. Res., 111, D21206, doi:10.1029/2006JD007150, 2006.

Vohra, K. G., Subba Ramu, M. C., and Muraleedharan, T. S.: An experimental study of the role of radon and its daughter products in the conversion of sulphur dioxide into aerosol particles in the atmosphere, Atmos. Environ., 18, 1653-1656, 1984.

Wiedensohler, A.: An approximation of the bipolar charge distribution for particles in the submicron size range, J. Aerosol Sci., 19, 387-389, 1988.

Willeke, K. and Baron, P. B., Aerosol Measurements; Principle, Techniques, and Applications, Van Nostrand Reinhold, New York, USA, ISBN 0-442-00486-9, 1993.

Winkler, P. M., Steiner, G., Vrtala, A., Vehkamäki, H., Noppel, M., Lehtinen, K. E. J., Reischl, G. P., Wagner, P. E. and Kulmala, M.: Heterogeneous nucleation experiments bridging the scale from molecular ion clusters to nanoparticles, Science 319, 1374-1377, 2008.

Yu, F., Wang, Z., Luo, G., and Turco, R.: Ion-mediated nucleation as an important global source of tropospheric aerosols, Atmos. Chem. Phys., 8, 2537-2554, 2008, http://www.atmos-chem-phys.net/8/2537/2008/. 